\title{
Componer la vida artísticamente: aproximación a la génesis filosófica del concepto de autopoiesis
}

Composing life artistically: approach to the philosophical genesis of the concept of autopoiesis

\section{Cristóbal Javier Rojas Gil}

Grado en Filosofía y Máster en Filosofía, Ciencia y Ciudadanía, Universidad de Málaga, España (javinba06@hotmail.com)

RESUMEN: Las páginas que conforman este breve ensayo proveerán al lector de un atlas en el que podrán encontrarse algunas claves hermenéuticas que prometen ser de utilidad a la hora de comprender el modo en el que ha ido gestándose la idea que postula que la vida pueda ser pensada en tanto que obra artística. De esta forma, el propósito del artículo que nos ocupa será el de aventurar una hipótesis filosófica acerca de la procedencia de dicha noción y, de modo simultáneo, el de dilucidar algunos de los factores determinantes en la configuración de este fenómeno de la vida artística.

PALABRAS CLAVE: Filosofía, Arte, Vida, Estética, Novelización.

\begin{abstract}
These pages would want to be a map for the reader which he would use to find some hermeneutics keys and to understand the way of the thought that postulates life as an art work. Thus, the purpose of the essay is to suggest a philosophical hypothesis about the origin of this notion and, at the same time, to explain some of the decisive factors in the process of shaping of this phenomenon of artistic life.
\end{abstract}

KEYWORDS: Philosophy, Art, Life, Aesthetics, Novelizatio 
En cualquier caso, debido a la superficialidad de nuestro intelecto, vivimos en una ilusión permanente: es decir, para vivir tenemos necesidad de arte en cada momento. Nuestro ojo nos fija a las formas. Pero si somos justamente los que poco a poco nos hemos educado dicho ojo veremos que en nosotros mismos se impone una fuerza artística. Friedrich Nietzsche

Comenzar a explorar el asunto de la autopoiesis exige que seamos capaces de ofrecer una definición precisa del ámbito de problematización del que vamos a ocuparnos. Permitamos que sea Michel Foucault quien nos introduzca en la cuestión. El autor de Las palabras y las cosas, en una entrevista, plantea la siguiente pregunta (Rabinow y Dreyfus, 2001, p. 269):

"Lo que me sorprende es que en nuestra sociedad el arte se haya convertido en algo que sólo se relaciona con los otros objetos y no con los individuos o con la vida. Ese arte es algo especializado, o que es producido por expertos que son artistas. Pero, ¿podría alguien convertir su vida en una obra de arte? ¿Por qué puede la lámpara de una casa ser un objeto artístico, pero no nuestra propia vida?”.

En los años en los que Foucault enuncia estas palabras, él mismo se encuentra en el ojo del huracán de un proceso caracterizado por un viraje en el que diferentes objetos cotidianos, tales como una lámpara, una mesa de ajedrez e incluso un urinario, adquieren paulatinamente el rango de artísticos. Otro incipiente motivo destacable es el de permitir que el artista emplee su cuerpo a fin de exhibir sus creaciones. Foucault, según se aprecia, va un paso más allá, proponiendo que sea en este caso la vida del sujeto la que se eleve al rango de arte. Más aún: su propuesta es que sea alguien quien aspire a convertir $s u$ vida en una obra de arte.

Con la intención de perfilar los contornos de este fenómeno ético-estético podrían ofrecerse una larga serie de consideraciones diferentes. Sin embargo, y puesto que el cometido de este artículo no es el de definir la vida artística como tal sino el de afrontar la búsqueda de su procedencia, quisiera remitirme sólo a una consideración, concretamente a aquella que podemos hallar insistiendo en el testimonio del que nos provee Foucault. Dice así el autor: “A partir de la idea de que el yo no es algo que nos es dado, pienso que no hay una única consecuencia práctica: tenemos que crearnos a nosotros mismos como obras de arte" (Rabinow y Dreyfus, 2001, p. 270). Sólo cuando seamos capaces de considerar la propia subjetividad, el yo, como algo por hacer (fragmentado y des-hecho), se manifestará en nosotros la necesidad de hacernos, de componernos, de asegurarnos una unidad; y, todo ello, siguiendo el dictamen de una fuerza artística que nace en el propio sujeto. 
Comprender este exceso filosófico nos insta a perseguir el desarrollo del concepto a través de una senda genealógica. Desde Sócrates hacia la contemporaneidad, haciendo escala en autores como Montaigne, Kierkegaard, Nietzsche o Barthes, trataremos de clarificar el linaje al que se adhiere la pregunta que aquí se acaba de presentar.

\section{Sócrates: la vida en el punto de mira}

En Apología de Sócrates, Platón ofrece por escrito la defensa de su maestro frente al tribunal que le había condenado injustamente. En ese texto quisiera ubicar la raíz, o, si cabe, la semilla, del fenómeno de la vida artística. Para comprender esta clasificación propongo leer un pasaje de dicha obra, valiéndome en todo caso de una mirada centrada en advertir el motivo que estimula esta reflexión. Dice Sócrates en el juicio que le costaría la vida (Platón, 2014, p. 76):

"Y si añado que el bien máximo para un hombre es reflexionar cada día acerca de la virtud y otras cosas sobre las que me habéis oído conversar cuando me sometía a examen tanto a mí mismo como a los demás, y que para un hombre una vida no examinada no merece ser vivida, todavía creeríais menos en lo que digo".

Sócrates determina en el fragmento citado que una de las principales ocupaciones a las que debe dedicarse el hombre es a la de reflexionar en torno a la existencia propia. Esta aseveración contiene tras de sí el mismo imperativo que podía leerse inscrito en la entrada del templo de Apolo en Delfos: Conócete a ti mismo. En consonancia con lo expuesto, podemos afirmar que, en la época clásica, de entre las ocupaciones del filósofo, destacaba la del conocimiento de sí. Predomina el cuestionamiento radical de la existencia, pues sólo de ese modo el filósofo logrará comprender aquello que, en definitiva, él es.

Dediquemos algunas líneas a pensar la vida del hombre más sabio de Atenas a fin de extraer de ella algunas provisiones que nos permitan avanzar. Tres factores, a modo de pistas hermenéuticas, pueden destacarse en la historia de este filósofo. El primero de ellos está referido directamente al elemento historiográfico. La historia de Sócrates, tal y como la conocemos, los hechos de su vida y las acciones que nos llevan a valorar su tan admirable empresa, no las narra en primera persona, sino que, muy al contrario, esta nos llega a través del testimonio que nos ofrecen otros autores de la antigüedad como Platón y Jenofonte. 
Dicha consideración nos hace reparar en un segundo hito. Si nos ceñimos estrictamente al caso platónico comprobaremos cómo la figura de Sócrates que nos presenta su discípulo es, sospechosamente, la de un hombre admirable por una infinitud de vicisitudes. Si por algo se caracteriza su vida es por erguirse como ejemplar.

El tercer y último factor, aparejado a los dos anteriores, permite que completemos la hipótesis por la que podría pensarse que cuando se discute o teoriza sobre Sócrates se hace irremediablemente sobre una figura de la ficción. Platón construye, por medio del relato, una ficción de su maestro en la que este es siempre el principal interlocutor y aquel que vence las discusiones con el resto de atenienses, especialmente con los sofistas. Platón, como Jenofonte y Diógenes, hace del filósofo sin obra que es Sócrates un personaje.

\section{Montaigne: el relato de sí mismo}

Debemos transitar desde la Grecia clásica hacia la modernidad en la que se inscribe Michel de Montaigne para continuar construyendo la genealogía que nos ocupa en este momento. En este autor se advierte con facilidad una importante influencia de la máxima a la que nos hemos referido, según la cual el hombre ha de invertir sus esfuerzos en el conocimiento de sí. Alcanzada la madurez, Montaigne decidió retirarse del ámbito público, recluyéndose en su torre, con la única meta de realizar un concienzudo ejercicio de introspección. Me parece de especial relevancia la pregunta que sirvió de cabecera para la totalidad de los ensayos que escribió el autor en su aislamiento, la cual quedaría así formulada: ¿Qué soy yo?

En síntesis, el proyecto de Montaigne no parece alejarse demasiado del de Sócrates, como por otra parte tampoco del que se propone Descartes. A poco que lo pensemos podremos hallar un primer punto de discrepancia: en Montaigne advertimos un matiz que no está presente en Sócrates, a saber, el de la vida como literatura. Montaigne y la obra que él hace de sí por medio de la narración de sus ensayos avanzan al unísono, formando un todo (establece orden en el desorden que sólo es). El propio Montaigne lo dice por escrito: "Nosotros, mi libro y yo, vamos de acuerdo y con la misma marcha. En otros casos puédese elogiar la obra y criticar al obrero, por separado; en este no: si se ataca al uno, se ataca al otro" (2005, p. 788). Destaquemos un movimiento de importancia: se transita en este momento desde el biografismo socrático hacia el autobiografismo del francés. 
Comentemos ahora el caso cartesiano. Al comienzo del Discurso del método algunas anotaciones nos invitan a pensar que el proyecto cartesiano tiene un marcado interés autobiográfico, al igual que el de su predecesor Montaigne. Insistiendo en la lectura de las páginas del Discurso se detecta el que quizás sea el punto de discrepancia fundamental. En pocas palabras: Descartes escribe para saber qué es el hombre, movido por una curiosidad biológica o científica; nada más lejos del propósito de Montaigne, quien escribe con el único objetivo de saber quién es él, en la particularidad y dispersión que su vida presenta, a fin de volver su vida algo modelable. El deseo de Montaigne es el de capturar la existencia efímera y frágil en la que se halla sumergido para, con dichos materiales, inventarse un nuevo yo. Nos topamos en este instante con la aseveración de Foucault: considerar la subjetividad vacua conlleva irremediablemente que el yo naufrague en un mar de incertidumbres, tornándose como algo por hacer. Para poder construirlo artísticamente debemos antes proveernos de él, o sea, adueñárnoslo, capturarlo, apresarlo. El danés Kierkegaard nos brinda unas palabras interesantes con las que glosar esta voluntad de aprehensión de sí mismo (1994, p. 83):

"La desesperación en la cual se quiere ser uno mismo exige la conciencia de un yo infinito, que en el fondo no es más que la forma más abstracta del yo, la más abstracta de sus posibles. Es ese el yo que el desesperado quiere ser, desprendiéndolo de toda relación con un poder que lo ha planteado, arrancándolo a la idea de la existencia de un poder semejante. Con ayuda de esa forma infinita, el yo quiere desesperadamente disponer de sí mismo o, creador de sí mismo, hacer de su yo el que él quiere devenir, elegir lo que admitirá o no en su yo concreto. Pues esta no es una creación cualesquiera, es la suya, y ella comporta, en efecto, necesidad, límites, es un determinado preciso, particular, [...] y negándose a endosar su yo, a ver su tarea en ese yo que le ha tocado en suerte, quiere mediante la forma infinita que se encarniza en ser, construir él mismo su yo".

Disponer de sí mismo para construirse siguiendo un criterio propio. Quisiera denominar este ejercicio de proveerse de unidad, de cohesionar uno mismo los fragmentos que componen la ficción que sólo somosı, como novelización de la vida propia.

Dos razones nos permiten comprender esta elección. En esta actividad, cuyo epicentro gira en torno a la premisa de llegar a ser lo que se es2, el individuo no busca sino construir una novela de sí mismo que presente aquellos signos que él decreta como propios. Del mismo modo, tal y como puede apreciarse en los ensayos de Montaigne, en la narración el individuo aparece alisado por el relato, el

\footnotetext{
"En La voluntad de poder escribe Nietzsche: "El "sujeto" no es más que una ficción" (2014, p. 260).

${ }^{2}$ Tal es el subtítulo que toma la mencionada obra autobiográfica de Nietzsche, a saber, Ecce Homo.
} 
cual le describe y limita. Él es en su obra lineal y atemporal: es un personaje de novela, circunscrito al marco que estipula la misma. No hay personaje sin un contexto, de este modo, Montaigne es un personaje de la novela que él mismo ha inventado en sus ensayos, al igual que Sócrates lo es en los diálogos de su discípulo, Nietzsche en Ecce Homo e incluso Roland Barthes en su autobiografía titulada Barthes por Barthes.

\section{Nietzsche: la vida artística}

Doy a leer unas lúcidas líneas de El nacimiento de la tragedia, escritas por Nietzsche en su juventud, con el convencimiento de que nos pondrán tras la pista de lo que trataremos de perfilar en este apartado (2004, p. 46-47):

El ser humano no es ya un artista, se ha convertido en una obra de arte: para suprema satisfacción deleitable de lo Uno primordial, la potencia artística de la naturaleza entera se revela aquí bajo los estremecimientos de la embriaguez. El barro más noble, el mármol más precioso son aquí amasados y tallados, el ser humano, y a los golpes de cincel del artista dionisiaco de los mundos resuena la llamada de los misterios eleusinos.

La consecuencia directa de convertir la propia vida en "el barro más noble", además de transformarla en objeto de tratamiento artístico es, en opinión de Nietzsche, que el sujeto mismo termine volviéndose una obra de arte: su propia obra de arte. Esta idea no dista mucho de la del neodadaísta Yves Klein, a quien se le atribuye la siguiente sentencia: "Un pintor no pinta más que una sola obra maestra: él mismo, constantemente" (Bourriaud, 1999, p. 60), como tampoco del protagonista de la novela El retrato de Dorian Gray, de quien dice su autor: "Para él, ciertamente, la Vida era la primera y la más grande de las artes, y todas las demás no eran más que una preparación para ella" (Wilde, 1999, p. 171).

Alcancemos el final del ensayo definiendo grosso modo algunos de los aspectos más significativos que podemos atribuir a este fenómeno estético. El primero de ellos es el que Wilde anota en la frase citada: la existencia vital del individuo es la piedra angular de su arte. Sin vida no hay artista, sin circunstancias no hay invención. Y lo que es más importante: dicha vida artística es posible en la medida en que para el sujeto su existencia es un fin en sí mismo. Vive por y para hacer de sí una obra de arte. 
Postular la existencia como juego trae aparejado el segundo de los aspectos a señalar: el artista de sí mismo constantemente está inventándose, o sea, inventando modos de vida diversos. Abundemos en lo último que se ha dicho citando a Barthes, concretamente su Barthes por Barthes: "Tout ceci doit être considéré comme dit par un personnage du roman - ou plutôt par plusieurs" (1975, p.123)3. La máxima apropiación de aquello que soy es también una exacerbada ficcionalización de la idea de sujeto, en la que la identidad queda eclipsada por diferentes personajes que componen aquello que uno es. Apropiarme de mí, hacer de mí un personaje de novela, es también dejar de ser aquello que soy. Para comprender esta idea a la que acabo de referirme me parece imprescindible citar a Ortega(1995, p. 233):

Pero ese sentido estético del vivir que tanto nos importa conquistar exige una educación especial, una técnica y una sabiduría peculiares. No basta para adquirirlo aprender las ciencias o cultivar las artes; es preciso hacerse, más o menos, un especialista en vidas, un dilettante apasionado de modos de vivir.

Formarnos en ese "sentido estético del vivir" implica que nos convirtamos en un "dilettante apasionado de modos de vivir". Dilettante, constantemente siendo y des-siendo. Lo es Marcel Duchamp, presentándose con un nombre diferente al suyo o travistiéndose, tomando la identidad de Rrose Sélavy; también lo es Fernando Pessoa, quien dependiendo del poema es Alberto Caeiro, Álvaro de Campos o Bernardo Soares4; así como también lo es Sophie Calle, la artista contemporánea que quiso participar de la experiencia que suponía ser Maria Turner después de que Paul Auster escribiera acerca de ella en Leviatán.

Finalizo con una última cita que, en el mejor de los casos, servirá para dar crédito a los planteamientos aquí elaborados: "Ser libre quiere decir carecer de identidad constitutiva, no estar adscrito a un ser determinado, poder ser otro del que se era y no poder instalarse de una vez y para siempre en ningún ser determinado" (Ortega, 2008, p. 39).

\footnotetext{
3 "Todo esto debe ser considerado como algo dicho por un personaje de novela - o, más bien, por varios" [La traducción es del autor].

${ }^{4}$ Fernando Pessoa, narrándose a través de una multitud de personajes ficticios que de algún modo suponen los fragmentos de su propio yo, escribe al comienzo de su inconcluso Libro del desasosiego: "Este libro es la autobiografía de quien nunca ha existido” (2014, p. 26). ¿Emplea Pessoa la escritura autobiográfica precisamente para, al contrario de lo que pudiera pensarse, dejar de ser quién es? ¿Dejar de ser quién soy acaso no implica llegar a ser aquello que quiero ser? Queda pendiente profundizar sobre este asunto. Cito a Foucault: "Escribo para perder el rostro. No me pregunten quién soy" (1979, p. 29).
} 


\section{Conclusión}

El cauce discursivo que se ha prolongado hasta aquí se erigía con el propósito de revelar la posible génesis filosófica de la idea del sujeto auto-componiéndose artísticamente. La pregunta nos la ofreció Foucault, y siguiéndole a él, podemos decir que los autores Sócrates, Montaigne y Nietzsche nos han permitido pulir un relato con el que exponer la tesis hermenéutica que aún reclama ser desarrollada. Quedaría aventurar, además de la genealogía del concepto, también su arqueología.

El estudio ha concluido arrojándonos a la actualidad. Digamos algo acerca de ella. Una característica que considero fundamental en el presente que habitamos es el de la confusión. Constantemente nos hallamos intentando vencer el vacío que nos invade, viviendo en función de imágenes cada vez más sofisticadas y siendo lo que somos sosteniéndonos en las fotografías que tomamos. Tal es la desidia que define nuestra época.

El melancólico Pessoa, con un tono manifiestamente dramático, expresa una idea que podríamos reconocer como síntoma de nuestros días: "Yo mismo no sé si este yo que os expongo en estas páginas tortuosas existe realmente o si es tan sólo un concepto estético y falso que me he formado de mí mismo" (Pessoa, 2014, p. 51).

¿Ese yo al que me esfuerzo en parecerme, al que persigo infatigablemente a través de redes sociales, me representa? Cabría aventurar una nueva conjetura, en este caso en forma de confrontación: en un extremo, aquel sujeto que dedica su empeño a hacer de sí una obra de arte, y en el otro, la figura del impostor, afanado en parecerse a aquello que dice ser. En cualquier caso, algo podría decirse de ambos: operan sin afuera. Ser ficción implica no poder(se) salir. ¿Acaso sí?

Termino citando a Sartre. Doy a leer una frase de La náusea convencido de que el lector será capaz de advertir en ella una consecuencia actual que subyace en los estratos que definen nuestro tiempo. En una página de su diario, el perturbado Roquentin escribe: "Pero ya no veo nada; es inútil que hurgue en el pasado, sólo saco restos de imágenes y no sé muy bien lo que representan, ni si son recuerdos o ficciones" (Sartre, 1984, p. 45). 


\section{Referencias bibliográficas}

BARTHES, Roland (1975). Roland Barthes par Roland Barthes. Éditions du Seuil: Paris.

FOUCAULT, Michel (1979). La arqueología del saber. Traducción de A. Garzón del Camino. Siglo veintiuno editores: México.

KIERKEGAARD, Søren (1994). Tratado de la desesperación. Traducción de J. E. Holstein. Edicomunicación: Barcelona.

MONTAIGNE, Michel de (2005). Ensayos completos. Traducción de A. Montojo. Cátedra, Madrid, 2005.

NIETZSCHE, Friedrich (2000). El libro del filósofo. Traducción de A. Bersain. Taurus: Madrid.

NIETZSCHE, Friedrich (2004). El nacimiento de la tragedia. Traducción de A. Sánchez Pascual. Alianza Editorial: Madrid.

NIETZSCHE, Friedrich (2014). La voluntad de poder. Traducción de Aníbal Froufe. Editorial Edaf: Madrid.

ORTEGA Y GASSET, José (1995). El sentimiento estético de la vida (Antología). Edición de J. L. Molinuevo. Tecnos: Madrid.

ORTEGA Y GASSET, José (2008). Historia como sistema y otros ensayos de filosofía. Edición de P. Garagorri. Alianza Editorial: Madrid.

PESSOA, Fernando (2014). El libro del desasosiego. Traducción de Antonio Sáez Delgado. Pretextos: Valencia.

PLATÓN (2014). Apología de Sócrates. Menón. Crátilo. Traducción de O. Martínez García. Alianza editorial: Madrid.

RABINOW, Paul y DREYFUS, Hubert (2001). Michel Foucault: Más allá del estructuralismo y la hermenéutica. Traducción de R. C. Paredes. Ediciones Nueva Visión: Buenos Aires.

SARTRE, Jean-Paul (1983). La náusea. Traducción de A. Bernández. Seix Barral: Barcelona.

WILDE, Oscar (1999). El retrato de Dorian Gray. Traducción de J. L. López Muñoz. Alianza Editorial: Madrid. 